\title{
Calanus and environment in the eastern North Atlantic. I. Spatial and temporal patterns of C. finmarchicus and C. helgolandicus
}

\author{
Benjamin Planque ${ }^{1,2, *}$, Jean-Marc Fromentin ${ }^{2}$ \\ 'Sir Alister Hardy Foundation for Ocean Science, The Laboratory, Citadel Hill, Plymouth PL1 2PB, United Kingdom \\ ${ }^{2}$ Laboratoire d'Océanographie Biologique et d'Ecologie du Plancton Marin, URA2077, Station Zoologique, BP 28, \\ F-06230 Villefranche-sur-Mer, France
}

\begin{abstract}
Spatial and temporal patterns of Calanus finmarchicus and C. helgolandicus (Copepoda, Calanoida) were investigated in the northeast Atlantic and the North Sea from 1962 to 1992. The seasonal cycle of $C$. finmarchicus is characterised by a single peak of abundance in spring, whereas the seasonal cycle of $C$. helgolandicus shows 2 abundance maxima, one in spring and one in autumn. The former species mainly occurs in northern regions (limited by the $55^{\circ} \mathrm{N}$ parallel in the North Sea and by the $50^{\circ} \mathrm{N}$ parallel in the open ocean). The latter species shows 2 types of spatial patterns, occurring in the Celtic Sea during spring and in the Celtic Sea plus the North Sea in autumn. Differences in seasonal spatial patterns of Calanus species may result from different responses to the environment, uItimately due to different life cycle strategies, different vertical distributions, opposite temperature affinities and interspecific competition. Futhermore, results reveal that annual means of abundance are closely related to annual maxima and to spatial extensions of the species. It also appears that the long-term trends of the 2 Calanus species are opposite: C. finmarchicus shows a clear downward trend in abundance, while C. helgolandicus presents an upward one.
\end{abstract}

KEY WORDS: Calanus Long-term changes Seasonal spatial patterns - Eastern North Atlantic . North Sea Continuous Plankton Recorder survey

\section{INTRODUCTION}

The high variability at low frequencies of plankton communities has been quite recently described by means of long-term monitoring (Russell et al. 1971, Cushing \& Dickson 1976, Bernal 1979, 1981). Longterm fluctuations of zooplankton appear to result from environmental changes, rather than purely biological processes (Colebrook 1978, Chelton et al. 1982). Recent studies demonstrated the importance of environmental factors such as sea temperature, oceanic currents, turbulence, wind stress and nutrients on plankton changes (Colebrook \& Taylor 1979, 1984, Colebrook 1982, 1985. 1986, Dickson et al. 1988, Radach et al. 1990, Fransz et al. 1991).

\footnotetext{
·E-mail: bp@wpo.nerc.ac.uk
}

In most of these works, zooplankton was considered as a whole and the behaviour of total zooplankton was principally studied. Our purpose was to determine the specific responses of individual zooplankton species that have different physiological and biological properties to environmental changes. We studied 2 calanoid copepod species, Calanus finmarchicus and C. helgolandicus. These species were chosen because: (1) they constitute the major component of the northeast Atlantic and North Sea zooplankton in terms of biomass, numbers and trophic role (Williams et al. 1994. Gislason \& Astthorsson 1995); (2) they are closely related, play a similar role in the ecosystem and their biology and physiology have been largely described (Marshall \& Orr 1972, Williams 1985).

To understand the specific responses of these 2 Calanus species to their environment, we first have to describe their spatial and temporal patterns. The pur- 
pose of this article is to identify and compare seasonal cycles, spatial patterns, and long-term fluctuations in abundance of the 2 species, as well as their potential link to environmental variables.

\section{METHODS}

Sampling. Data were provided by the Continuous Plankton Recorder (CPR) survey. The CPR is a highspeed plankton sampler designed to be towed from commercially operated 'ships of opportunity' over long distances. CPR are towed in the surface layer ( 7 to $8 \mathrm{~m}$ depth) and, due to mixing induced by the ship towing the CPR, the 0 to $20 \mathrm{~m}$ layer is sampled (H. G. Hunt pers. comm.). Plankton samples are collected every 20 nautical miles $\left(37 \mathrm{~km}\right.$ ), corresponding to about $3 \mathrm{~m}^{3}$ of filtered water. The survey started in 1931 in the North Sea, and was extended over the North Atlantic at the end of the 1950s (Warner \& Hays 1994). However, Calanus finmarchicus and $C$. helgolandicus species were not routinely distinguished until the late 1950s, thus we have only used the data collected during the period 1962 to 1992 . Only stage $V$ copepodites and adults are routinely identified to species level in the CPR survey, and we present here data on these stages only. We focused on the eastern North Atlantic, where the sampling was constant and regular during 1962-92 (see Warner \& Hays 1994) and where the 2 species commonly occur (Oceanographic Laboratory Edinburgh 1973, Colebrook 1986). Plankton data consist of about 72000 samples ( 2300 per year).

The CPR survey provides information on the subsurface distribution of species. Therefore, changes in abundance presented in this study only refer to the sub-surface layer. However, Calanus species undergo ontogenetic vertical migrations (Williams \& Conway 1980, Hirche 1983, Williams 1985) and consequences of this behaviour on sub-surface changes in Calanus abundance will be discussed.

Analyses. Species abundances in each sample were log-transformed using the $\log (x+1)$ function (Colebrook 1975). Monthly data were interpolated in order to obtain a series of regular grids. Interpolation was performed by kriging, the most suitable method for a nonstandard sampling (Cressie 1993). A total of 372 grids were calculated, 1 for each month from 1962 to 1992, and resulted in 372 maps. In the eastern North Atlantic, grid nodes (map pixels) with a minimum of $70 \%$ of data during 1962-92 were selected. Remaining missing values were estimated using the ZET method (Zagoruiko \& Yolkina 1982), an iterative multiple regression model. The final grid consisted of 224 nodes representing a map of 224 pixels of $8575 \mathrm{~km}^{2}$ surface each (Fig. 1).
In order to assess variations in the spatial extension of each species, we defined a variable called 'spatial coverage' For each monthly map, pixels with at least 1 individual were coded 1 and others were coded 0 . Spatial coverage of each monthly map was defined by the ratio of pixels coded 1 to the total number of pixels and was given as a percentage $10 \%$ indicates that there is no pixel with at least 1 individual, $100 \%$ indicates that there is at least 1 individual in every pixel).

Annual abundances correspond to the mean of abundance from January to December. Annual maxima of abundance are defined as the highest monthly abundances of each year. Seasonal cycles are calculated from the means of each month of the 1962-92 series

Comparison of long-term series was done using the Pearson correlation on original series and detrended ones. Correlations on detrended series were used to reveal relationships that were not due to long-term trends. Cross-correlation was tested by a Monte-Carlo approach (5000 simulations).

\section{RESULTS}

\section{Seasonal cycles}

The mean seasonal cycle of Calanus finmarchicus abundance, calculated from the 1962-92 series, shows

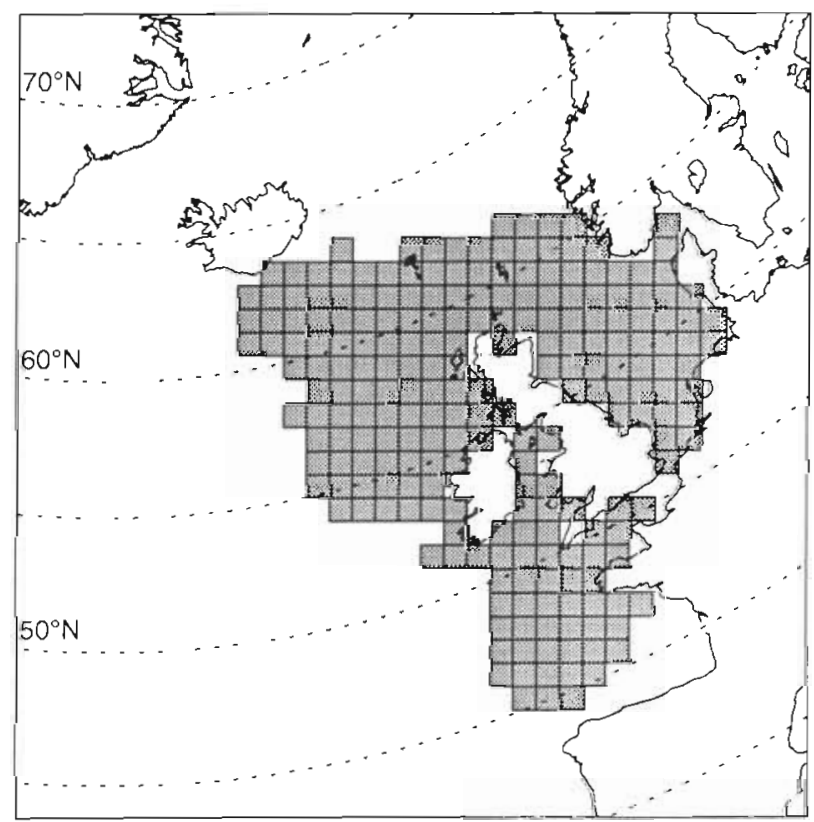

Fig. 1 Study area. Selection of pixels in this area was based on the regularity of the Continuous Plankton Recorder (CPR) survey from 1962 to 1992 and on the numbers of missing values by pixels 
a clear peak of abundance during spring, i.e. April to June, and a plateau from July to September (Fig 2a). The seasonal cycle of spatial coverage follows the same pattern, indicating that these 2 variables are closely related and that the number of organisms per surface unit is constant all through the year (Fig. 2a).

The mean seasonal cycle of Calanus helgolandicus abundance is quite different (Fig. 2b). There are 2 abundance maxima during the year The first one occurs from May to June, and the second and major one from September to October. Contrary to $C$. finmarchicus, abundance and spatial coverage are not totally similar (Fig. 2b). The shapes of the 2 curves are close, but spatial coverage is at a higher level during autumn. This result indicates either that the mean number of organisms per surface unit is lower during this period or that the species spatial dispersal is higher or that there has been a reorganisation of the species vertical distribution.

The seasonal pattern of Calanus finmarchicus is reproducible from year to year; in $90 \%$ of the cases the annual maximum of abundance occurs around May. For C. helgolandicus the situation is a bit more complicated, with annual maximum abundance generally occurring around September (75\% of cases). but in some years around June (25\% of cases). For both species, mean abundance is very low during winter, but organisms are still present in the surface layer.

\section{Seasonal spatial patterns}

\section{Calanus finmarchicus}

During winter, abundances in the surface layer are low and the species distribution is restricted to northern areas, south of Iceland and south of Norway (Fig. 3a). At the beginning of spring, abundances and spatial extension increase, mainly in the northern North Sea and between Scotland and Iceland. The annual abundance maximum appears clearly on the May-June map. The spatial distribution is characterised by 2 areas of very high abundances, south of Iceland and south of Norway. The southern limit is around the $55^{\circ} \mathrm{N}$ parallel in the North Sea and the $50^{\circ} \mathrm{N}$ parallel in the open ocean. During summer, there is a general decline in abundance and spatial extension decreases in the open ocean (southern limit of the distribution moves north to around the $55^{\circ} \mathrm{N}$ parallel). In autumn, rather high abundance always occurs in the northem North Sea and spatial restriction continues, organisms being confined further north than in summer. In November-December, there is a drop in abundance and Calanus finmarchicus is limited to the northern North Sea.

\section{Calanus helgolandicus}

During winter, the species distribution is confined mainly in the south of the area studied and in the eastern part of the North Sea (Fig. 3b). At the beginning of spring, there is a rise in abundance. Populations extend further south into the Bay of Biscay and disappear from the North Sea surface waters. From May to June, a strong increase in abundance occurs in the Celtic Sea, and populations expand from the south of the area to the North of Ireland. Summer is marked by a decline in abundance and changes in the spatial pattern: organisms move northward, penetrate into the North Sea and vanish from the Bay of Biscay surface waters. Maxima of abundance and spatial coverage, corresponding to the second peak of abundance, are illustrated by the SeptemberOctober map. As in spring, organisms are numerous in the Celtic Sea. However, this period is characterised by high abundance in the surface water of the North Sea and the Shetland-Orkney Isles that was not observed in spring. In November-December, abundances and spatial coverage decline; remaining organisms are located in the Celtic Sea and the North Sea
Fig. 2. Mean seasonal cycles of (a) Calanus finmarchicus and (b) C. helgolandicus calculated over the entire area from 1962 to 1992. Solid lines: $\log (x+1)$ of abundances; dashod lines: spatial coverage (percentage of pixels containing at least 1 individual)
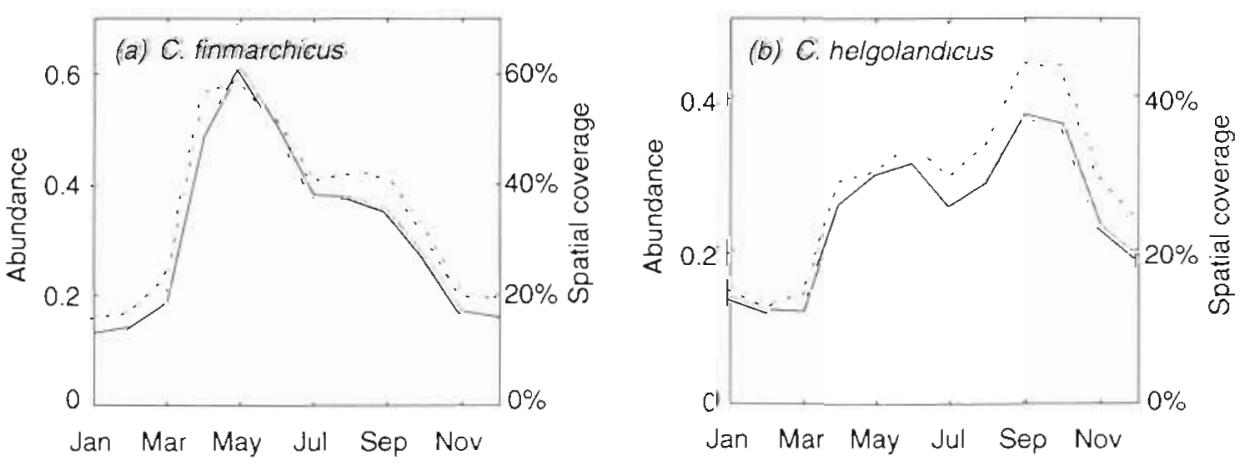

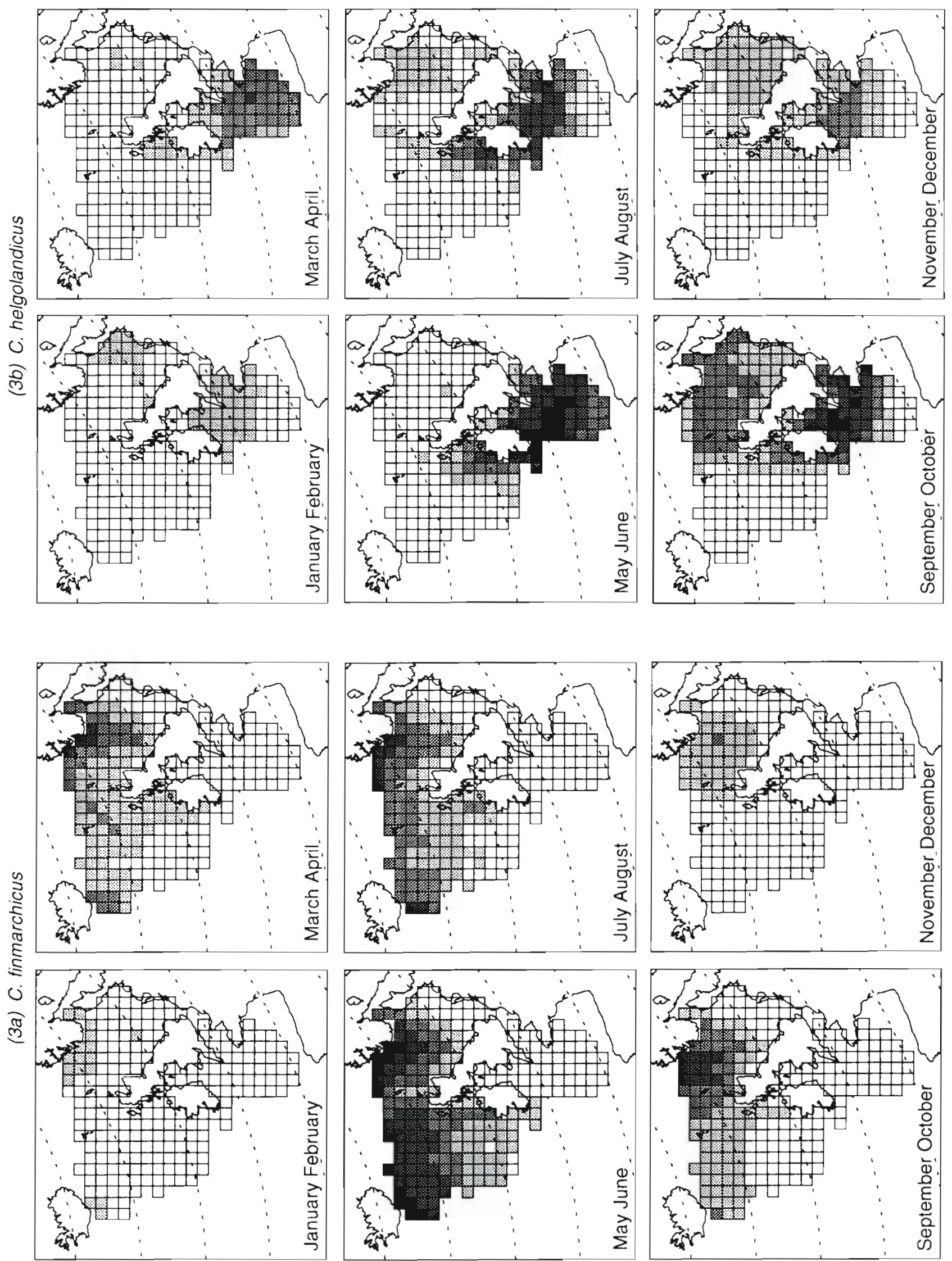

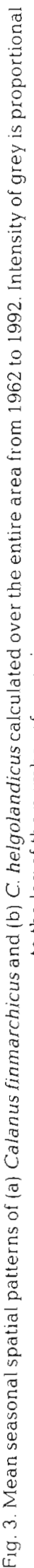




\section{Calanus finmarchicus versus $C$. helgolandicus spatial patterns}

Mean spatial coverage of Calanus finmarchicus and $C$. helgolandicus was 33.2 and $28.5 \%$ of the studied area respectively, but the 2 species can temporarily cover larger areas, mainly in spring for $C$. finmarchicus (up to $77 \%$ of the studied area in June 1978) and in autumn for C. helgolandicus (up to $82 \%$ of the studied area in September 1984). Nevertheless, the 2 species do not reside in the same regions (Rees 1957, Jaschnov 1970 , Colebrook 1986). To assess the geographical affinity of each species and their area of co-occurrence, we computed from the 1962-92 series the following index (I) for each pixel:

$$
I=\left|\frac{f-h}{f+h}\right|
$$

where $f$ is the number of months in which the abundance of $C$. finmarchicus in the pixel is equal to or greater than 1 (organism per sample); $h$ is the number of months in which the abundance of C. helgolandicus in the pixel is equal to or greater than 1 (organism per sample). Index values are included between 0 and 1 . The value of the index for a pixel is 0 when $C$. helgolandicus occurs as often as $C$. finmarchicus in the pixel. Conversely, when only 1 of the 2 species occurs, the value of the index is 1 .

The map of this index (Fig. 4) indicates a latitudinal gradient with a zone of co-occurrence of the 2 species in the middle of the studied area and 2 specific regions, north and south. Calanus helgolandicus is preferentially located in southeastern areas and specifically around Brittany, whereas $C$. finmarchicus is dominant in northwestern areas and specifically to the south of Iceland. Specific zones do not exactly match the regions of maximum abundance, situated in the Celtic Sea for $C$. helgolandicus and south of Iceland and south of Norway for $C$. finmarchicus. The region of $\mathrm{Co}-$ occurrence is very wide and extends over the North Sea and in the eastern North Atlantic from 52 to $57^{\circ} \mathrm{N}$. The 2 Calanus species co-occur in surface waters of the eastern North Atlantic during spring only and in the surface waters of the North Sea during summer and autumn only (Fig. 3).

\section{Long-term changes}

Annual variations in the 2 species abundance over the entire area from 1962 to 1992 are shown in Fig. 5. Calanus finmarchicus displays a clear downward trend over the period (Fig. 5a). The main periods of high abundance are 1962-66 and 1977-80. Years 1967-76 and $1981-86$ are characterised by average abundances and $1987-92$ by low numbers. On the other hand, $C$. helgolandicus shows a clear upward trend (Fig 5b). The period $1967-76$ also displays average abundance, whereas low abundances occur in 1962-66 and 1977-81. In contrast, the end of the series, 1982-86 and 1989-92, is marked by the highest abundances.

Although for both species most of the variability occurs at the scale of a few years, autocorrelation analyses (Legendre \& Legendre 1984) do not reveal any dominant cycle. Correlation between the 2 species is significant at the $5 \%$ level $(\mathrm{r}=-0.4)$. This correlation vanishes when it is calculated on detrended series $(r=-0.03)$, indicating that the opposite relationship between the 2 series is mainly due to long-term trends. Nonetheless, cross-correlation between Calanus finmarchicus abundance and $C$. helgolandicus abundance in the following year is higher $(\mathrm{r}=-0.55)$ and significant for both original $(p<0.01)$ and detrended series $(r=-0.4, p<0.05)$. Cross-correlations with a lag greater than $1 \mathrm{yr}$ are not significant. Thus, the opposition between annual fluctuations in abundance of the 2 species mainly occurs with a delay of 1 yr.

We calculated the correlation between the annual mean abundance and the annual maximum abundance on the 1962-92 series. For both species, correlations are significant at the $1 \%$ level $(r=0.77$ for Calanus finmarchicus and $\mathrm{r}=0.62$ for $C$. helgolandicus). Thus, annual abundances of both species are strongly linked to spring abundance for C. finmarchicus and spring/ autumn abundance for $C$, helgolandicus.

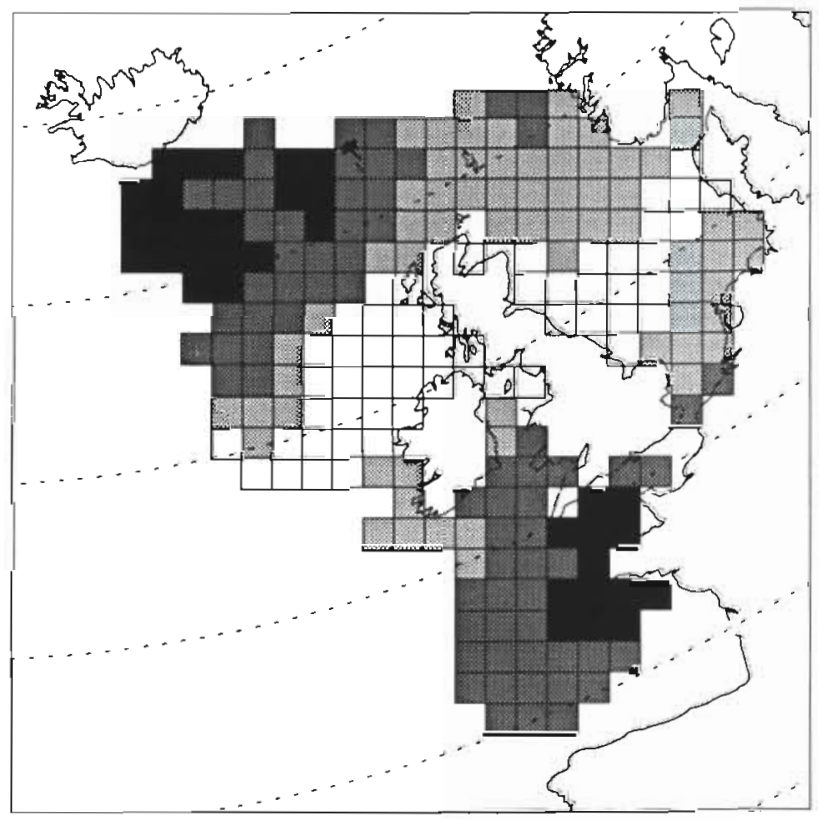

Fig. 4. Co-occurrence of Calanus finmarchicus and C. helgolandicus. Intensity of grey is proportional to the species ratio (see index $I$ in the text). White squares: $C$. helgolandicus occurs as often as C. finmarchicus; black squares: 1 of the 2 species predominates 



Fig. 5. Annual log of abundances (January to December means) of (a) Calanus finmarchicus and (b) C. helgolandicus. Solid lines: year-to-year fluctuations and polynomial fits; dashed lines: means over the 1962-1992 period

Correlations between annual abundance and spatial coverage are very high $(r=0.96$ for Calanus finmarchicus and $\mathrm{r}=0.97$ for $C$. helgolandicus, $\mathrm{p}<1 \times$ $\left.10^{-9}\right)$. This very strong link indicates that fluctuations in abundance cannot be dissociated from fluctuations in spatial extension.

\section{DISCUSSION}

\section{Relationship between phytoplankton and Calanus}

The spring phytoplankton bloom occurs in the surface layer of the whole studied area, as noted by Colebroók (1982), and both Calanus species take advantage of this spring increase in phytoplankton abundance. Nevertheless, the 2 populations mainly remain spatially apart, with $C$. finmarchicus in the North Sea and the eastern North. Atlantic and $C$. helgolandicus mainly to the south of the British Isles. During summer, there is a general decline in phytoplankton biomass (Colebrook 1982) that would explain the decrease in the abundance of the 2 copepods. The autumn period is crucial and is characterised by a higher level of phytoplankton biomass in the North Sea (Colebrook 1982). However, high abundance of $C$. finmarchicus in the near-surface layer only occurs in the northern North Sea, while C. helgolandicus is abundant in both southern regions and North Sea. The spatial extent of the latter species is probably supported by the North Sea phytoplankton production during this period. Finally, phytoplankton resources are generally exploited by the 2 species in geographically separated regions, except north of Ire- land during spring and in the northern North Sea during autumn, where the 2 copepod species occur simultaneously.

\section{Relationship between temperature and Calanus}

The 2 Calanus species have specific physiological responses to temperature (Hirche 1987, 1990, Carlotti et al. 1993). C. finmarchicus is known to be a coldtemperate water species whereas $C$. helgolandicus is a warm-temperate one (Rees 1957, Jaschnov 1961, 1970, Matthews 1967, 1969, Colebrook 1982, Williams 1985). Although the 2 species tolerate a large temperature range, their geographical distribution is related to the geographical temperature gradient (Jaschnov 1961, Williams 1985). Thus, the northern location of C. finmarchicus and its limitation south by the 50 to $55^{\circ} \mathrm{N}$ parallel during its period of maximum spatial coverage probably result from the species' affinity to cold temperatures. Its peak of maximum abundance occurs in spring when temperatures are relatively low and phytoplankton abundant. In autumn, while phytoplankton abundance is maintained at a sufficient level, temperatures are probably too high to allow a second peak of abundance of $C$. finmarchicus. Conversely, the opposite spatial distribution of $C$. helgolandicus can be explained by its warm-temperate temperature affinity. Its preferential zone is located in the south. During spring, while temperatures are relatively low and phytoplankton abundant, this species remains in southern waters. Conversely, summer-autumn warming probably allows the species to extend north and graze the important phytoplankton biomass of the North Sea. Competition for resources between $C$. finmarchicus and C. helgolandicus in the North Sea is probably related to the temperature seasonal cycle, $C$. finmarchicus and $C$. helgolandicus being respectively favoured in spring and in autumn. However, Williams \& Conway (1980) give evidence that the vertical temperature gradient is responsible for differences in vertical distributions between the 2 Calanus species and between stages within species. The development of the seasonal thermocline also affects both species' vertical distribution and results in their separation in the water column (Williams 1985). Furthermore, the life cycle of Calanus species is characterised by seasonal ontogenetic vertical migration and overwintering strategies (Hirche 1983). Thus, differences in life cycles and overwintering strategies between C. finmarchicus and C. helgolandicus (Hirche 1983, 1984) are likely to be responsible for different reponses of the 2 species to seasonal changes in temperature. Nonetheless, fluctuations in abundance of Calanus 
species in the surface layer probably reflect true changes in abundance that can be altered by seasonal vertical migration of the stage $\mathrm{V}$ copepodites and adults.

\section{Relationship between currents and Calanus}

Seasonal and spatial changes of both Calanus species are related to temperature and phytoplankton changes but also to advective transport. Hydrodynamism in the area is characterised by the inflow of North Atlantic waters into the North Sea through the northwestern North Sea and the English Channel, and an outflow along the Norwegian coasts (Otto et al. 1990, Backhaus et al. 1994). This feature provides a physical support to the penetration of $C$. helgolandicus into the North Sea during summer. Residual circulation cells south of Norway and in the Celtic Sea (Otto et al. 1990) probably favour the persistence of Calanus populations in these regions all through the year.

Seasonal and spatial distributions of the 2 Calanus species probably result from specific biological processes (reproduction, feeding, overwintering) and changes in environmental conditions (resource availability, sea temperature, stratification and advective transport). It is reasonable to postulate that abundance and spatial coverage of each species are maximal when optimal environmental conditions are encountered. C. finmarchicus reaches its higher abundances in spring when phytoplankton is abundant and temperature relatively low. In autumn, phytoplankton is probably sufficient to support a second peak in abundance but temperature conditions might not be optimal for this species. Furthermore, a high proportion of stage $V$ copepodites have probably already migrated to deeper water to constitute the overwintering stock (Hirche 1983). This can explain the unimodal seasonal cycle of $C$. finmarchicus and its restriction to northern areas since July, despite a current regime propitious to a southern extension. C. helgolandicus takes advantage of the spring phytoplankton bloom only in southern regions where temperatures are highest. Although C. helgolandicus is advected into the North Sea through the year, it mainly expands into this basin in autumn. The species probably takes advantage of the North Sea phytoplankton production in autumn when temperatures are higher. Furthermore, the species benefits from the relatively low abundance of $C$. finmarchicus in the surface layer during this period. Thus, differences in seasonal spatial patterns of Calanus species might result from different responses to the environment, ultimately due to different life cycle strategies, different vertical distributions, opposite temperature affinities and interspecific competition.

\section{Long-term changes}

Our results show important year-to-year fluctuations in abundance that are associated with variations in annual abundance maxima and changes in spatial coverage. Annual abundance maximum appears to control total annual abundance. A drop in maximum abundance is not compensated by high abundance during other periods of the year These copepods have several cohorts per year (Marshall \& Orr 1972), and these results indicate that a perturbation during the period of maximum abundance may have some important repercussions on the following generations.

An increase in the abundance of both species is always associated with a rise in their spatial coverage. Although long-term changes in abundance and in spatial coverage are closely related, seasonal cycles of these 2 variables are similar in $C$. finmarchicus, but not in $C$. helgolandicus. These results indicate that the number of organisms per surface unit stays constant all through the year for the former species, but varies for the latter. In autumn, the dispersal of C. helgolandicus is higher than in spring and the number of individuals per pixel is lower Thus, the autumn peak of abundance probably results from the species' capacity to extend spatially, rather than from local increases in abundance. This suggests that annual abundance in near-surface waters clepends on the spatial extension of optimal environmental conditions

A noticeable result is the opposition in long-term trends of the 2 Calanus species' abundance. C. finmarchicus is the most abundant copedod and follows a clear downward trend, similar to that described by Colebrook et al. (1984) and Dickson et al. (1988) for total copepods and total zooplankton. On the contrary, C. helgolandicus shows a clear upward trend that was unexpected in view of these previous works. This opposition in long-term trends is confirmed by the significant negative correlation between the 2 species. Furthermore, cross-correlation on the detrended series $C$. finmarchicus and $C$. helgolandicus in the following year, is also significant. This indicates that the opposition between the 2 species also occurs at a shorter time scale. This is clear during the years 1962-66, 1977-80 and 1987-92. Thus, temporal patterns of the 2 species are opposite at short and long time scales but the causes of opposition and of the delay of 1 yr are rather obscure.

\section{CONCLUSION}

It emerges from our results that these 2 Calanus species, which fulfil a comparable function in the ecosystem, display different and sometimes opposite 
spatial and temporal patterns. Previous works showed that global events could control marine populations. Dickson et al. (1988) postulated that the long-term increase in the northerly wind component over the eastern North Atlantic, between 1950 and 1980, induced a decline of both phytoplankton and zooplankton. If the long-term decline of $C$. finmarchicus fits with this scheme, this mechanism is not adequate to explain C. helgolandicus long-term increase.

A large-scale atmospheric oscillation, which modifies winds regime, occurs in the North Atlantic (Rogers 1984, 1990, Lamb \& Randy 1987, Mann \& Lazier 1991). This oscillation is comparable to another global atmospheric event, the El Niño Southern Oscillation (Rasmusson \& Wallace 1983, Enfield 1989, Mann \& Lazier 1991), which changes wind stress, hydrodynamism and sea temperature over the Pacific and is known to impact pelagic communities (Cushing \& Dickson 1976, Barber \& Chavez 1983, McGowan 1985, Dandonneau 1986, Mysak 1986). This oscillation could be responsible for the changes in abundance of Calanus species observed in the present work. However, the studied area is situated in a heterogeneous environment, strongly affected by coastal influences such as regional temperature gradient, local currents, tide effects, pollutant discharges and freshwater inflows. This regional frame could locally control zooplankton abundance fluctuations

Finally, it has to be determined whether Calanus finmarchicus and $C$. helgolandicus populations respond to different local environmental conditions or if they specifically respond to hydrological and climatical changes induced by the North Atlantic Oscillation.

Acknowledgements. We thank all past and present members of the CPR survey team and all its financial supporters. This study was carried out by the 'Programme National d'Océanographie Côtière' IFREMER/INSU, the MAST program of the European Commission and the French Ministry of Research. We also thank Andrew J. Warner for his help on the CPR database, Prof. Paul Nival, Michelle Etienne, Philip C. Reid, Frédéric Ibañez and the referees for their advice and comments on the manuscript

\section{LITERATURE CITED}

Backhaus JO, Harms IH, Krause M. Heath MR (1994) An hypothesis concerning the space-time succession of Calanus finmarchicus in the northern North Sea. ICES J Mar Sci 51:169-180

Barber RT, Chavez FP (1983) Biological consequences of the 1982-83 El Niño. Science 222:1203-1210

Bernal PA (1979) Large-scale biological events in the California Current. CalCOFI Rep 20:89-101

Bernal PA (1981) A review of the low frequency response of the pelagic ecosystem in the California current. CalCOFI Rep 22:49-62
Carlotti F, Krause M, Radach G (1993) Growth and development of Calanus finmarchicus related to the influence of temperature: experimental results and conceptual model. Limnol Oceanogr 38:1125-1134

Chelton DB, Bernal PA, McGowan JA (1982) Large-scale interannual physical and biological interaction in the California Current. J Mar Res 40:1095-1125

Colebrook JM (1975) Automatic data processing methods. Bull Mar Ecol 8:123-142

Colebrook JM (1978) Continuous Plankton Records: zooplankton and environment North-East Atlantic and North Sea. Oceanol Acta 1:9-23

Colebrook JM (1982) Continuous Plankton Records: seasonal variations in the distribution and abundance of plankton in the North Atlantic Ocean and the North Sea. J Plankton Res 4:435-462

Colebrook JM (1985) Continuous Plankton Records: overwintering and annual fluctuations in the abundance of zooplankton. Mar Biol 84:261-265

Colebrook JM (1986) Continuous Plankton Records: the distribution and standing crop of the plankton of the shelf and ocean to the west of the British Isles. Proc R Soc Edinburgh 88:221-237

Colebrook JM, Robinson GA, Hunt HG, Roskell J, John AWG, Bottrell $\mathrm{HH}$, Lindley JA, Collins NR, Halliday NC (1984) Continuous Plankton Records: a possible reversal in the downward trend in the abundance of the plankton of the North Sea and the northeast Atlantic. J Cons Int Explor Mer 41:304-306

Colebrook JM, Taylor AH (1979) Year to year changes in the sea-surface temperature North Atlantic and North Sea. 1948-1974. Deep Sea Res 26A:825-850

Colebrook JM, Taylor AH (1984) Significant time scales of long-term variability in the plankton and the environment. Rapp P-v Cons Int Explor Mer 183:20-26

Cressie NAC (1993) Statistics for spatial data. Wiley, New York

Cushing DH, Dickson RR (1976) The biological response in the sea to climatic changes. Adv Mar Biol 14:1-122

Dandonneau Y (1986) Monitoring the sea surface chlorophyll concentration in the tropical Pacific: consequence of the 1982-83 El Niño. Fish Bull 84:687-695

Dickson RR, Kelly PM, Colebrook JM, Wooster WS, Cushing DH (1988) North winds and production in the eastern north Atlantic. J Plankton Res 10:151-169

Enfield DB (1989) El Niño past and present. Rev Geophys 27: $159-187$

Fransz HG, Colebrook JM, Gamble JC, Krause M (1991) The zooplankton of the North Sea. Neth J Sea Res 28:1-52

Gislason A, Astthorsson OS (1995) Seasonal cycle of zooplankton southwest of Iceland. J Plankton Res 17:1959-1976

Hirche HJ (1983) Overwintering of Calanus finmarchicus and Calanus helgolandicus. Mar Ecol Prog Ser 11:281-290

Hirche HJ (1984) Seasonal distribution of Calanus finmarchicus (Gunnerus) and C. helgolandicus (Claus) in a Swedish fjord. Crustaceana (Suppl) 7:233-241

Hirche HJ (1987) Temperature and plankton. Il. Effects on respiration and swimming activity in copepods from the Greenland Sea. Mar Biol 94:347-356

Hirche HJ (1990) Egg production of Calanus finmarchicus at low temperatures. Mar Biol 106:53-58

Jaschnov VA (1961) Water masses and plankton. 1. Species of Calanus finmarchicus s.1. as indicators of definite water masses. Zool Zh 40:1314-1334

Jaschnov VA (1970) Distribution of Calanus species in the seas of the northern hemisphere. In Rev Ges Hydrobiol $55: 197-212$ 
Lamb PJ, Randy AP (1987) North Atlantic Oscillation: concept and an application. Bull Am Meteorol Soc 68:1218-1225

Legendre L, Legendre P (1984) Ecologie numérique, Vol 2, La structure des données écologiques. Masson, Paris

Mann KH, Lazier JRN (1991) Dynamics of marine ecosystems. Blackwell, Oxford

Marshall SM, Orr AP (1972) The biology of a marine copepod Oliver \& Boyd, Edinburgh

Matthews JBL (1967) Calanus finmarchicus s.1 in the North Atlantic. The relationship between $C$. finmarchicus s. str. C. glacialis and C. helgolandicus. Bull Mar Ecol 6:159-169

Matthews JBL (1969) Continuous Plankton Record: the geographic and seasonal distribution of Calanus finmarchicus s.1. in the North Atlantic. Bull Mar Ecol 6:251-273

McGowan JA (1985) El Niño in the southern California bight. In: Wooster WS, Fuharty DL (eds) El Niño North: El Niño effects in the Eastern Subarctic Pacific Ocean. University of Washington, Seattle, p 166-184

Mysak LA (1986) El Niño interannual variability and fisheries in the Northeast Pacific Ocean. Can J Fish Aquat Sci 43 $464-497$

Oceanographic Laboratory Edinburgh (1973) Continuous Plankton Records: a plankton atlas of the North Atlantic and the North Sea. Bull Mar Ecol 7:1-174

Otto L, Zimmerman JTF, Furnes GK, Mork M. Saetre R, Becker G (1990) Review of the physical oceanography of the North Sea. Neth J Sea Res 26:161-238

Radach G, Berg J, Hagmeier E (1990) Long-term changes of the annual cycles of meteorological hydrographic nutrient and phytoplankton time series at Helgoland and at LV ELBE 1 in the German Bight. Cont Shelf Res 10: $305-328$

This article was submitted to the editor
Rasmusson EM, Wallace JM (1983) Meteorological aspects of the El Nino/Southern Oscillation. Sclence 222:1195-1202

Rees CB (1957) Continuous Plankton Records: the distribution of Calanus finmarchicus (Gunnerus) in the North Sea and North-eastern Atlantic 1946-1953. Hull Bull Mar Ecol 4: 211-246

Rogers JC (1984) The association between the North Atlantic Oscillation and the Southern Oscillation in the Northern Hemisphere. Mon Weather Rev 112:1999-2015

Rogers JC (1990) Patterns of low-frequency monthly sea leve. pressure variability (1899-1986) and associated wave cyclone frequencies. J Clim 3:1364-1379

Russell FS, Southward AJ, Boalch GT, Butler EI (1971) Changes in biological conditions in the English Channel off Plymouth during the half century. Nature 234:468-470

Warner A.J, Hays GC (1994) Sampling by the Continuous Plankton Recorder survey. Prog Oceanogr 34:237-256

Williams R (1985) Vertical distribution of Calanus finmarchicus and $C$. helgolandicus in relation to the development of the seasonal thermocline in the Celtic Sea. Mar Biol 86 $145-149$

Williams R, Conway DVP (1980) Vertical distributions of Calanus finmarchicus and C. helgolandicus (Crustacea: copepoda). Mar Biol 60:57-61

Williams R, Conway DVP, Hunt HG (1994) The role of copepods in the planktonic ecosystems of mixed and stratified waters of the European shelf seas. Hydrobiologia 293 $521-530$

Zagoruiko NG, Yolkina VN (1982) Inference and data tables with missing values. In: Krishnaiah PR, Kanal LN (eds) Handbook of statistıcs. North Holland Publishing Company, p 493-500

Manuscript first received: August 14, 1995

Revised version accepted: November 9, 1995 